\title{
Application of an Evolutionary Algorithm for Parameter Optimization in a Gully Erosion Model
}

\author{
Francis Rengers $^{\mathrm{a}, 1,}$, Monte Lunacek ${ }^{\mathrm{b}}$, Gregory Tucker ${ }^{\mathrm{a}}$ \\ ${ }^{a}$ University of Colorado, Department of Geological Sciences, Boulder, CO \\ ${ }^{b}$ National Renewable Energy Laboratory, Golden, CO
}

\begin{abstract}
Herein we demonstrate how to use model optimization to determine a set of best-fit parameters for a landform model simulating gully incision and headcut retreat. To achieve this result we employed the Covariance Matrix Adaptation Evolution Strategy (CMA-ES), an iterative process in which samples are created based on a distribution of parameter values that evolve over time to better fit an objective function. CMA-ES efficiently finds optimal parameters, even with high-dimensional objective functions that are non-convex, multimodal, and non-separable. We ran model instances in parallel on a high-performance cluster, and from hundreds of model runs we obtained the best parameter choices. This method is far superior to bruteforce search algorithms, and has great potential for many applications in earth science modeling. We found that parameters representing boundary conditions tended to converge toward an optimal single value, whereas parameters controlling geomorphic processes are defined by a range of optimal values.
\end{abstract}

Keywords:

optimization, erosion, hydrology, landscape modeling

Email address: frengers@usgs.gov (Francis Rengers )

${ }^{1}$ Corresponding Author. Now at U.S. Geological Survey Golden, CO

Preprint submitted to Environmental Modelling and Software Articles February 25, 2016

(C) 2016. This manuscript version is made available under the Elsevier user license http://www.elsevier.com/open-access/userlicense/1.0/ 


\section{Software availability}

2 Name of software: GullyErosionProfiler1D

3 Developer: Francis Rengers

4 Contact address: U.S. Geological Survey, 1711 Illinois St., Golden, CO 80401.

5 frengers@usgs.gov

6 Year first available: 2012

7 Required software: Matlab

8 Source: https://github.com/csdms-contrib/gullyerosionprofiler1d

9 Availability and cost: GNU licensed freeware

Name of software: Param $_{\text {scan }}$

Developer: Monte Lunacek

Contact address: National Renewable Energy Laboratory, 15013 Denver W

Pkwy, Golden, CO 80401. Monte.Lunacek@nrel.gov

Year first available: 2014

Required software: Python

Program Language: Python

Source: https://github.com/frengers/JanusOpt/tree/master/src

Availability and cost: GNU licensed freeware

\section{Introduction}

Landscape change results from erosion and sedimentation processes that govern mass redistribution over long time periods; consequently, direct observation of landscape evolution is rarely possible. In order to properly understand how different geomorphic processes and landscape properties influence long-term erosion it is necessary to use models as proxies for large-scale landscape evolution. In most scenarios it is infeasible to construct physical models (Tucker, 2009) because important properties (such as rain-drop size) do not scale with model landscapes. As a substitute for direct observation, computer models serve as a useful alternative (Tucker and Hancock, 2010). 
Computational landform evolution models are composed of geomorphic transport laws (GTLs) (Dietrich et al., 2003), and a key challenge for computer modeling is choosing model parameter values for the GTLs. Parameters such as soil/rock erodibility are difficult to measure (Elliot et al., 1989; Prosser and Dietrich, 1995), therefore there is large uncertainty in the values assigned to these parameters. It is common to use steady and uniform values for some fluxes such as soil infiltration, which can presumably be estimated from field measurements; however, point infiltration rates can vary by orders of magnitude within the same watershed (Sharma et al., 1980). Consequently, process parameter values are often estimated by calibration (e.g. Barkwith et al. (2015)), which in turn requires comparison between observed and predicted landscape properties. Moreover, there is uncertainty in the initial and boundary conditions. Here we explore the use of optimization techniques to search for input values for these uncertain model parameters.

In this study, we have focused on a model of gully erosion. Gullies are deeply incised channels that migrate upstream via erosion from near-vertical headcuts, which are analogous to waterfalls in rivers (Figure 1). Water erosion in the model works to incise the gully vertically, and headcuts migrate upstream as they erode. The model was developed to explore how the processes of headcut erosion and water incision compete to form a concave-up longitudinal profile while maintaining a near-vertical headcut over hundreds of years (Rengers and Tucker, 2014). Our model, and the range of parameter values used in the model, are based on observations from the West Bijou Creek study site in eastern Colorado (Rengers and Tucker, 2014, 2015).

We applied the Covariance Matrix Adaptation Evolution Strategy (CMAES) (Hansen and Ostermeier, 2001), a parameter optimization scheme, to determine the most appropriate model parameter values. This approach is an inverse modeling method in which a model is run with different input parameters, and model output is subsequently compared to a known observed value. The best model parameters are determined as those that provided the closest fit between the model output and the observations.

\section{Background}

The overall longitudinal profile of a gully results from the competition between fluvial erosion and sedimentation processes (Rengers and Tucker, 2014). These processes are conceptualized in Figure 2. Wall failure as shown in the conceptual model can result from a variety of processes including: 


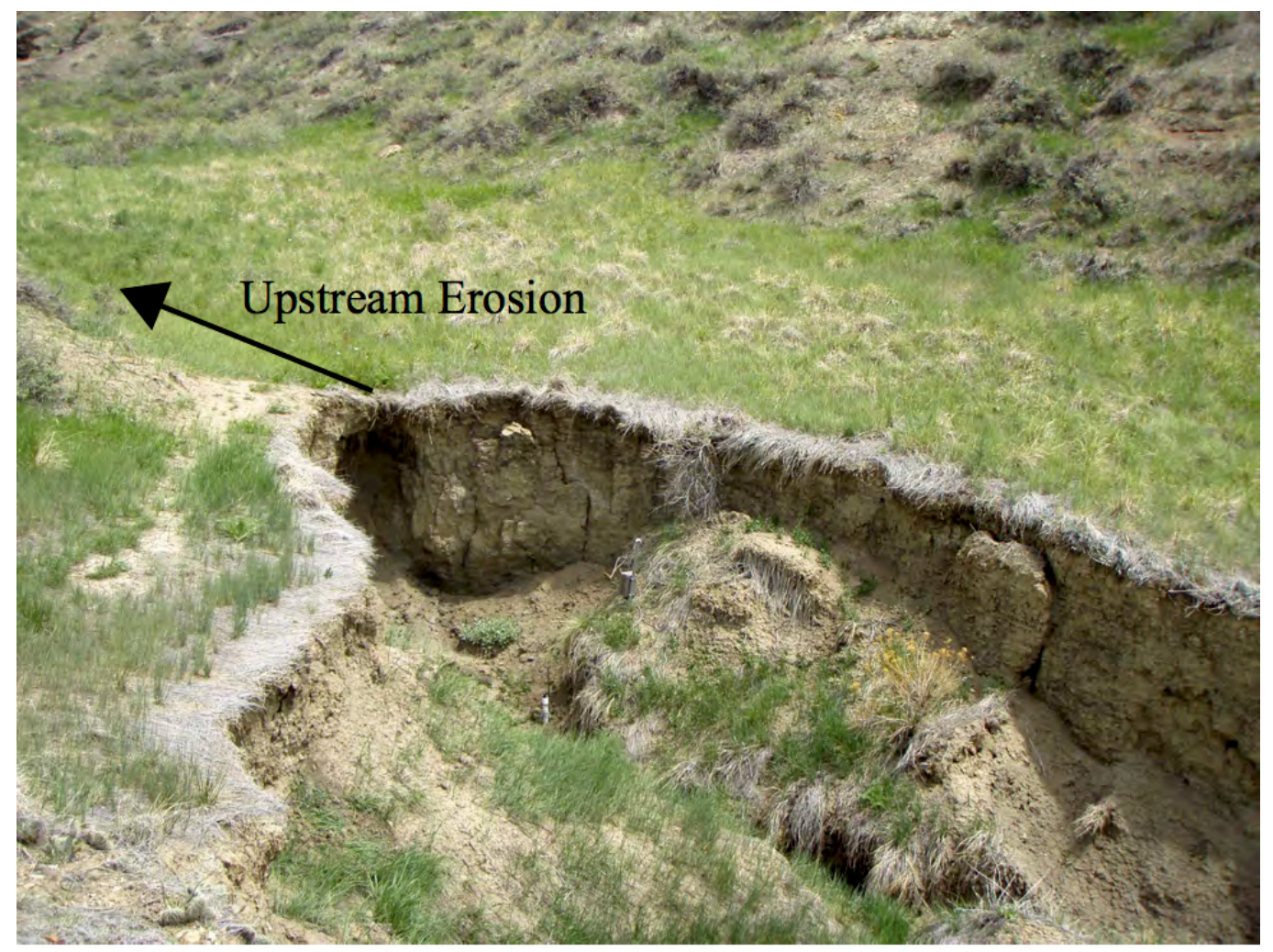

Figure 1: View of a headcut migrating upstream and extending gully erosion.

ground water seepage (Howard and McLane, 1988), piping (Verachtert et al., 2010), direct wash erosion over headcut walls (DeLong et al., 2014), mass failure (Bradford and Piest, 1980; Dietrich and Dunne, 1993; Istanbulluoglu et al., 2005; Montgomery, 1999), and plunge pool erosion through undercutting (Gardner, 1983; Gilbert and Hall, 1907; Stein and LaTray, 2002; Wohl et al., 1994). At our specific study site headcut wall failure was primarily associated with mass failure via soil saturation resulting from overland flow (Rengers and Tucker, 2015). Regardless of the specific process that governs headcut wall failure, erosion at the headcut has the ability to dramatically alter the overall profile of a gully over time depending on the rate of wall failure, and the influence of fluvial erosion (Gardner, 1983; Stein and Julien, 1993; Rengers and Tucker, 2014).

Three scenarios demonstrate the end-member possibilities required to dynamically maintain a gully headcut (Figure 3 ). First, if headcut wall failure 
occurs at a high rate, but fluvial processes are unable to transport the material away from the toe of the headcut; the headcut will become buried and a section of the gully channel will become locally convex (Figure 3a). Alternatively, if fluvial erosion operates at a high rate, eroding both the headcut lip and sediment deposited by headcut wall failure, then the gully channel will become locally concave (Figure $3 \mathrm{~b}$ ). Neither of the prior scenarios would preserve a discrete headcut step. A headcut is only preserved in the unique situation where fluvial erosion upstream of the headcut is limited and fluvial erosion downstream of the headcut is sufficient to remove material deposited from headcut wall failure (Figure 3c). This conceptual view of gully longitudinal profile evolution has been implemented in a numerical model in order to quantitatively test the hypothesis proposed in this conceptual framework (Rengers and Tucker, 2014).

\subsection{Study Site}

The gully erosion model is based on observations from a gully system that drains to West Bijou Creek on the high plains of eastern Colorado, USA (Rengers and Tucker, 2014, 2015). The underlying geology at the study site is a sequence of poorly lithified sandstone and shale units of Cretaceous to early Paleogene age (Barclay et al., 2003). The bedrock is shallow and weathers into cohesive clay-loam and loam soils (Entisols and Mollisols primarily). Site vegetation is primarily grassland, with sparse shrubs on steeper hillslopes. Both the soil and vegetation characteristics are believed to have an important control on gully formation and evolution (Rengers and Tucker, 2014).

Airborne lidar of the study site was flown on 23 April 2007 (National Center for Airborne Laser Mapping, 2007). The point data had a vertical accuracy of $10 \mathrm{~cm}$ and the point density was sufficient to construct a DEM with $1 m$ resolution (National Center for Airborne Laser Mapping, 2007).

\subsection{Governing equations}

Several models have been developed previously for gully erosion, but they do not explicitly account for headcut erosion (Woodward, 1999; Sidorchuk, 1999). Consequently, we use a model developed by Rengers and Tucker (2014) for gully erosion that explicitly accounts for headcut migration and focuses on the competition between fluvial erosion, headcut wall failure and sedimentation, and the resistive forces of vegetation and soil. This model does not specifically represent the processes that cause the initial gully incision and headcut formation, but rather starts with a headcut that can migrate 
over time. The major components of this model are displayed in Figure 2, and based on the following set of equations.

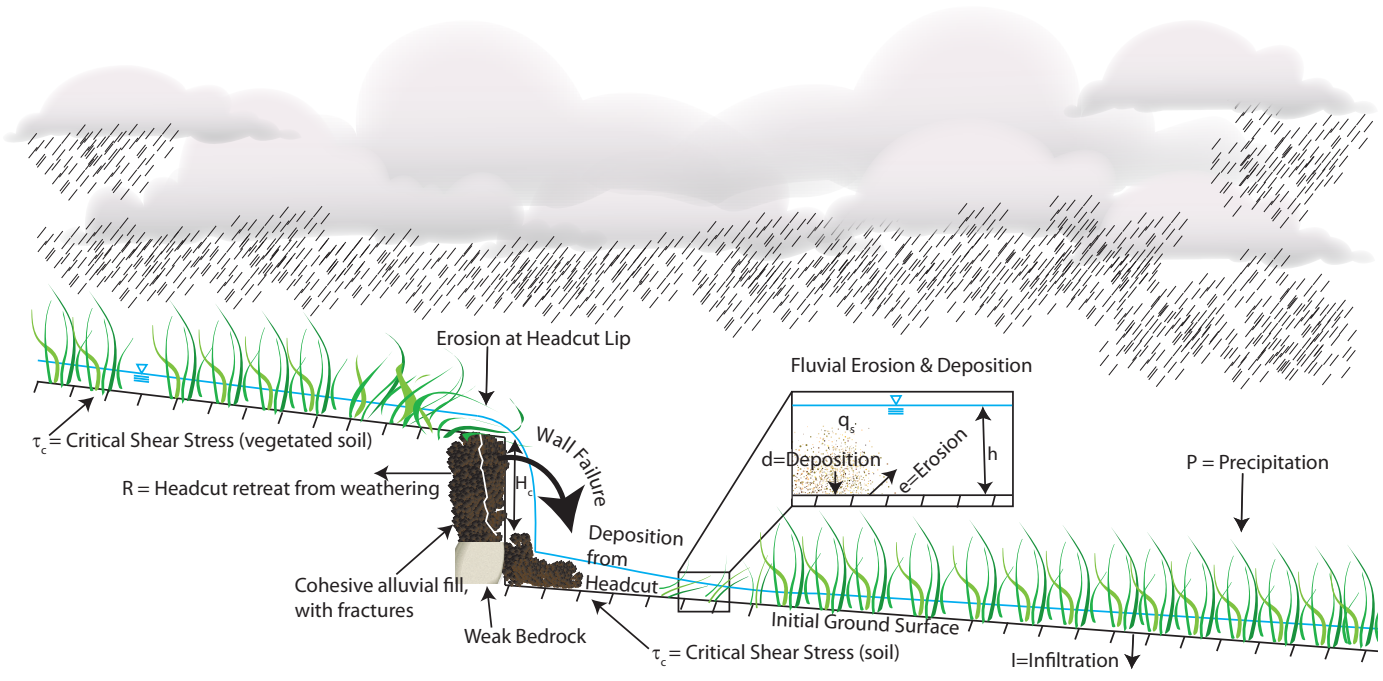

Figure 2: Conceptual diagram showing the model components.

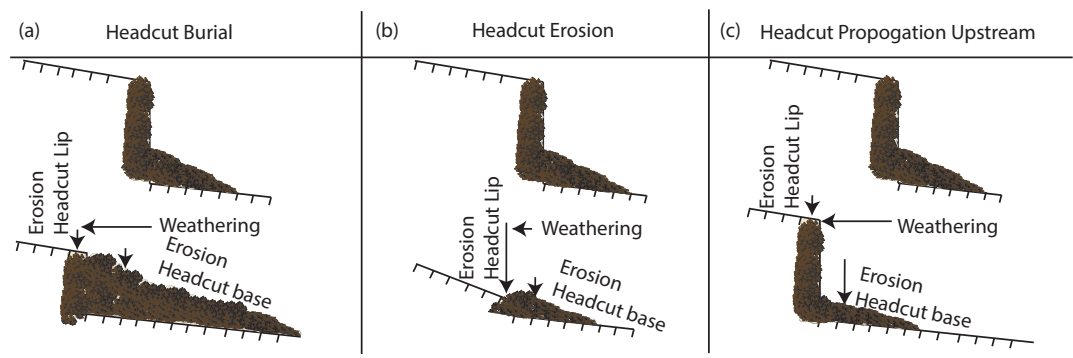

Figure 3: Three scenarios that show the possible evolution of a headcut in a gully environment. The arrow length indicates relative magnitude of each process. The top cartoon shows the starting condition, while the bottom cartoon shows the final condition. (a) Headcut burial from more deposition than erosion. (b) Headcut destruction due to more fluvial erosion than sedimentation. (c) Headcut propagation in the upstream direction, and preservation of the headcut step.

For overland flow, we assume steady-state discharge per unit width specified by:

$$
q=\frac{(P-I)}{B} A
$$


where $P$ [dimensions of length per time, $\left.L T^{-1}\right]$ is precipitation rate, $I\left[L T^{-1}\right]$ is infiltration rate, $B[L]$ is the bottom width of the channel, and $A\left[L^{2}\right]$ is drainage basin contributing area. Basin area is calculated from downstream distance along the valley profile, $x$, using Hack's law (Hack, 1957):

$$
A=f x^{H},
$$

with the values $f=0.19$ and $H=2.3$, which were derived from the DEM of the study catchment (Rengers and Tucker, 2014). The flow depth $h$ is calculated using a form of the Manning roughness equation,

$$
h=\left(\frac{q n_{m}}{S^{1 / 2}}\right)^{3 / 5},
$$

where $n_{m}$ is the Manning roughness coefficient, and $S$ is the channel bed slope. We used different Manning's $n_{m}$ parameters depending on the landcover type. The unique parameter name for $n_{m}$ representing grass is mann, and for bare soil it is $n b$ (Table 1).

Continuity of mass for bed sediment can be expressed as:

$$
\frac{\partial h_{T}}{\partial t}=\frac{d-e}{(1-\phi)}
$$

where $h_{T}$ is bed elevation, $d$ is the deposition flux [volume per unit time per unit bed area: $\left.L T^{-1}\right], e$ is the erosion flux $\left[L T^{-1}\right]$, and $\phi\left[L^{3} L^{-3}\right]$ is the porosity of sediment on the bed.

The erosion flux is modeled as a function of excess boundary shear stress,

$$
e=k\left(\tau-\tau_{c}\right)
$$

where $k\left[L^{2} T M^{-1}\right]$ is the erodibility constant, $\tau\left[M L^{-1} T^{-2}\right]$ is the bed shear stress, $\tau_{c}\left[M L^{-1} T^{-2}\right]$ is a critical shear stress below which erosion is negligible. Bed shear stress for steady, uniform, wide-channel flow is:

$$
\tau=\rho g h S
$$

where $\rho\left[M L^{-3}\right]$ is the density of water and $g\left[L T^{-2}\right]$ is gravitational acceleration. The deposition rate depends on the product of settling velocity and near-bed sediment concentration. Following Davy and Lague (2009), this can be expressed as: 


$$
\begin{array}{r}
d=d^{*} c_{s} \nu_{s}+\frac{q_{s L a t}}{B} \\
c_{s}=\frac{q_{s}}{q}
\end{array}
$$

where $d^{*}$ is a dimensionless parameter equal to 1 if the sediment flux is uniformly distributed through the water column, $c_{s}$ is sediment concentration in the water column (dimensionless), $\nu_{s}\left[L T^{-1}\right]$ is the settling velocity, $q_{s L a t}$ $\left[L^{2} T^{-1}\right]$ represents sediment coming into the channel from lateral sources, and $q_{s}\left[L^{2} T^{-1}\right]$ is the sediment discharge per unit width.

In addition to fluvial sediment, we also route the sediment derived from headcut wall retreat. The headcut is treated as a local source of sediment with a volume flux per unit valley width of:

$$
V_{r}=R H_{c}
$$

where $V_{r}\left[L^{2} T^{-1}\right]$ is the rate of sediment eroded per unit block length, $R$ [LT $\left.T^{-1}\right]$ is the retreat rate, and $H_{c}$ is the height of the headcut. Motivated by the observation that slump deposits tend to accumulate within a few meters of the main headcut face, we describe the depositional pattern of headcutderived sediment using an exponential pattern that decays downstream from the headcut face:

$$
d_{h c}(l)=\frac{V_{r}}{l *} e^{\frac{-l}{l *}}
$$

where $d_{h c}$ is the deposition rate due to wall collapse downstream of the headcut, $l$ is the distance downstream of the headcut, and $l *$ is a characteristic length scale for wall-collapse deposits. This rule mimics the observation that the thickness of slump deposits tends to taper downstream over a distance of one to several meters.

Equations 5-10 can be inserted into Equation 4 to obtain an equation for bed evolution:

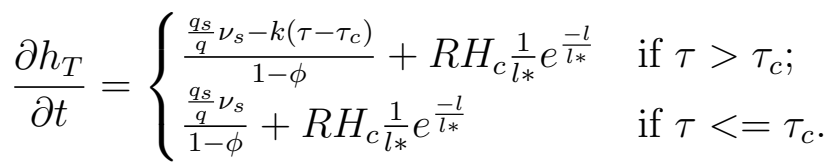

Equation 11 was solved numerically. Figure 4 shows an example of the model performance, which can be compared with an observed profile at each 
time-step. The observed profile was derived from the airborne lidar-derived DEM of the study site, with $1 m$ grid spacing.

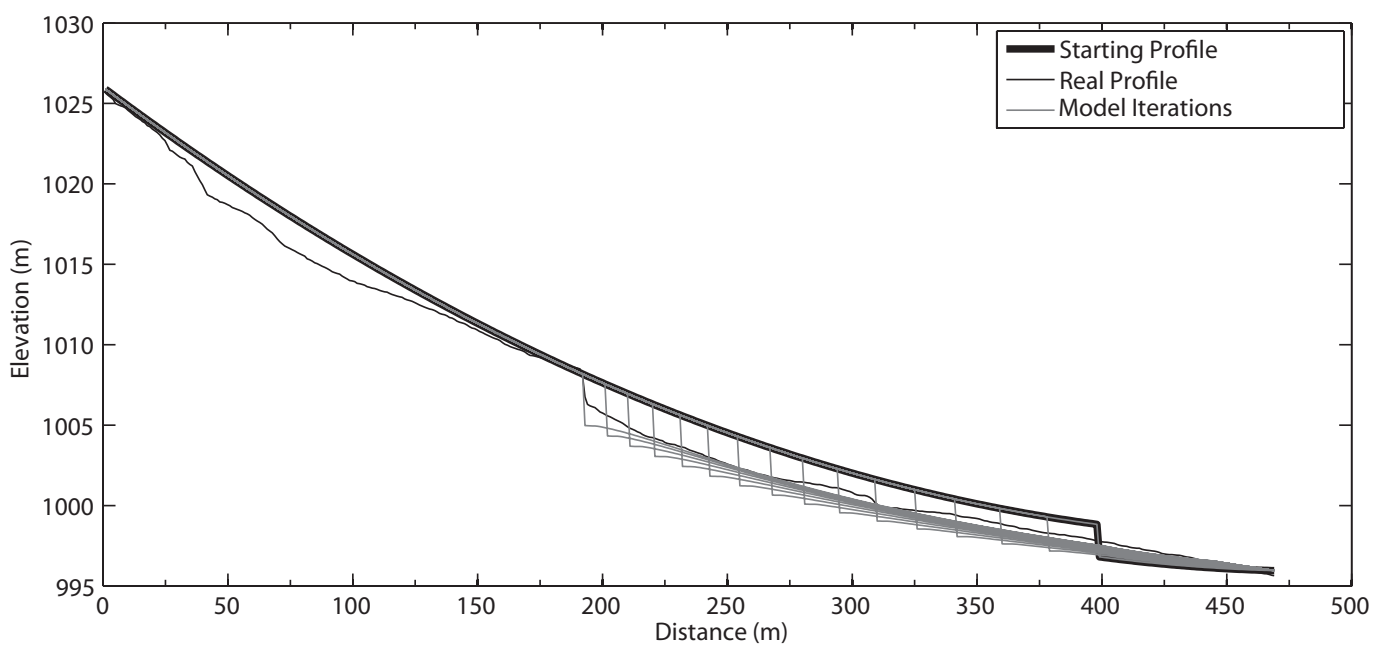

Figure 4: Example of a model run with an initial profile (thick black line) described by the polynomial in Equation 12. The black line is the observed profile. The thin gray line shows the model profile at different time steps.

\subsection{Parameters for Optimization}

We have selected several parameter values to optimize from the governing equations (Table 1). For precipitation we use a range from 5-100 $\mathrm{mm} / \mathrm{hr}$. In this model precipitation drives overland flow and thus low values of precipitation will not lead to flow depths sufficient to generate fluvial erosion of the channel bed. We chose a default value of $40 \mathrm{~mm} / \mathrm{hr}$ because site data show that most rain events larger than this rainfall intensity generate some overland flow. Our minimum precipitation value is sufficient to cause overland flow, but it is possible that larger rainfall intensities may be required to generate erosion over time. The infiltration default parameter value of 20 $\mathrm{mm} / \mathrm{hr}$ was determined based on infiltration measurements in the field. At the study site, the saturated infiltration rate was measured at 15 locations using a double-ring infiltrometer. The final (steady) infiltration rate at each 
site varied from $20 \mathrm{~mm} / \mathrm{hr}$ to $>300 \mathrm{~mm} / \mathrm{hr}$. During the infiltration tests, we anecdotally observed that the extremely large infiltration rate measurements were often underlain by soil cracks. Because the model infiltration rate represents an 'effective' value for the watershed as a whole, we used an optimization range of $5-45 \mathrm{~mm} / \mathrm{hr}$. This range represents potential 'effective' infiltration rates, and excludes extremely high measurements that are isolated to single patches within the watershed.

Our erosion parameters were obtained from published datasets. The range of values for the critical shear stress of grass-mantled soil $\left(\tau_{c}\right)$ was obtained from experimental work done by Prosser and Dietrich (1995). The critical shear stress for bare soil $\left(\tau_{c w}\right)$ was obtained from data on US Department of Agriculture field experiments (Elliot et al., 1989). The default value for $\tau_{c w}$ represents an experimentally determined value for clay-loam soil (Elliot et al., 1989), which is the dominant soil in the gully channels at the field site. Default Manning's roughness coefficient values were obtained from standard roughness values for overland flow on bare soil and grassy vegetation, respectively (Chow, 1959).

We also sought to optimize the initial starting profile for our model run. We varied the initial headcut height based on the range of headcut heights observed at the field site. A polynomial equation was used to fit a gently concave-up curve to the longitudinal profile measured with airborne lidar, in order to approximate an initial profile. This polynomial equation is written with three coefficients $\left(z_{1}, z_{2}\right.$, and $\left.z_{3}\right)$ as:

$$
z=z_{1} x^{2}+z_{2} x+z_{3}
$$

where $\mathrm{z}$ is the elevation of each cell in the model. The coefficients of this model were varied to determine the optimal starting condition.

Finally, the amount of time that the model simulates $(t)$ will influence the match between the measured and modeled profiles. Prior model simulations suggest that a time range between 400 and $450 \mathrm{yr}$ is appropriate (Rengers and Tucker, 2014) (Table 1).

\subsection{CMA-ES}

In order to find the optimal value for each parameter in the model, we use CMA-ES to efficiently analyze the many combinations of possible parameter values. This is done by running the model with different sets of parameter values. Each time the model is run with a unique set of parameter values 
Table 1: Parameters for Optimization

\begin{tabular}{ll}
\hline Parameter default value & $\begin{array}{l}\text { Value Range used for Opti- } \\
\text { mization }\end{array}$ \\
\hline Precipitation $(\mathrm{P})=40 \mathrm{~mm} / \mathrm{hr}$ & $5-100 \mathrm{~mm} / \mathrm{hr}$ \\
Infiltration $(\mathrm{I})=20 \mathrm{~mm} / \mathrm{hr}$ & $5-45 \mathrm{~mm} / \mathrm{hr}$ \\
Critical Shear Stress of Grass $\left(\tau_{c}\right)=140 \mathrm{~Pa}$ & $100-200 \mathrm{~Pa}$ \\
Critical Shear Stress of Bare Soil $\left(\tau_{c w}\right)=6.2 \mathrm{~Pa}$ & $2-200 \mathrm{~Pa}$ \\
Manning's coefficient for Bare Soil $(\mathrm{nb})=0.02$ & $0.01-0.055$ \\
Manning's coefficient for Grass $(\mathrm{mann})=0.05$ & $0.01-0.055$ \\
Initial Headcut Height $(\mathrm{h})=2 \mathrm{~m}$ & $1-4 \mathrm{~m}$ \\
Initial Profile Coefficient $(\mathrm{z} 1)=0.00008364$ & $8.0 \times 10^{-5}-9.5 \times 10^{-5}$ \\
Initial Profile Coefficient $(\mathrm{z} 2)=-0.09355$ & $-9.5 \times 10^{-2}--8.5 \times 10^{-2}$ \\
Initial Profile Coefficient $(\mathrm{z} 3)=1022.42$ & $1022-1025$ \\
Model simulation time $(\mathrm{t})=418 \mathrm{yr}$ & $400-450 \mathrm{yr}$ \\
\hline
\end{tabular}

an objective function is produced that describes the fit between the model output and the observed data. The goal of an evolution strategy is to evolve a set of parameter values that minimize the objective function. This best set of parameters will yield model output that best matches the observed data.

An evolution strategy is an iterative process where each iteration evaluates $\lambda$ randomly chosen points, with a point being a single set of parameter values. Only the best $\mu$ points are selected to be part of the next iteration. In our experiments, we used a $\mu=7$ and $\lambda=14$ strategy. The $\mu$ best points are used to produce a new set of $\lambda$ random points during the next iteration based on a normal probability distribution whose characteristics evolve over the course of the entire process. This is often referred to as the mutation distribution, and the exact way this distribution is defined and evolves differentiates the various evolution strategies.

Often the quality of the solution is not highly sensitive on the exact choice of $\mu$ or $\lambda$. Generally, problems that are particularly noisy or have more variables would require larger population values. The disadvantage of a larger population size is that it requires more evaluations per iteration, which decreases the optimization time, and can slow the rate at which the algorithm learns the topology of the problem. For our problem, $\lambda=14$ provided a good balance between optimization speed and quality of solution, and $\mu$ is typically set to half of $\lambda$.

An evolution strategy with Covariance Matrix Adaptation (CMA) uses 
a covariance matrix to explicitly rotate and scale the mutation distribution (Hansen and Ostermeier, 2001). The orientation and shape of the distribution are directly calculated based on the history of the best points evaluated and the shape of the best $\mu$ points in the current iteration. Hansen and Ostermeier (2001) define the reproduction phase from iteration $g$ to iteration $g+1$ as:

$$
x_{k}^{(g+1)}=\langle x\rangle_{\mu}^{(g)}+\sigma^{(g)} \mathbf{B}^{(g)} \mathbf{D}^{(g)} z_{k}^{(g+1)}
$$

where $z_{k}^{(g+1)}$ are randomly generated from an $N(0, I)$ distribution. This creates a set of base points that are rotated and scaled by the eigenvectors $\left(\mathbf{B}^{(g)}\right)$ and the square root of the eigenvalues $\left(\mathbf{D}^{(g)}\right)$ of the covariance matrix $C$. The single global step size, $\sigma^{(g)}$, is calculated based on the progress of the search process. Finally, the points are translated to center around $\langle x\rangle_{\mu}^{(g)}$, the mean of the $\mu$ best point of the iteration.

To compute covariance, CMA-ES uses a time-dependent portion of the search history. The evolution path, which is the average direction from the first iteration to the current iteration, updates after each iteration using a weighted sum of the current evolution path, $p_{c}^{(g)}$, and a vector that points from the mean of the $\mu$ best points in the iteration $g$ to the mean of the $\mu$ best points in iteration $g+1$. A principle-components analysis on the evolution path is used to update the mutation distribution.

When a larger population $(\lambda)$ is used, the best $\mu$ individuals may help describe the topology around the mean of the current iteration (N. Hansen and S.D. Müller and P. Koumoutsakos, 2003). This is called the rank- $\mu$ update. Hansen and Kern (2004) have empirically shown that CMA-ES performs well on noisy problems with many solutions when large populations and rank- $\mu$ updates are employed. Although in this specific study, the problem is not particularly noisy.

The distribution used by CMA-ES is initially isotropic. As a result, the initial value of $\sigma$ is important for exploration. However, the step-size $(\sigma)$ often increases before CMA-ES expoits a particular region. This makes the exact choice of the value less critical as long as it's not too small. Therefore, we chose a step-size of 0.1 , which, because the parameters of our problem are scaled between $[0,1]$, is sufficient for exploring the search space.

CMA-ES is not able to handle boundary constraints because it uses a normal distribution to sample the search space. Therefore, we used a constraintpenalty method similar to Hansen et al. (2009), to ensures that our parameter 
values are evaluated within the feasible region of our model. When a point falls outside of the model boundaries, we evaluate the point at the closest boundary and then apply a penalty to the solution that is proportional to the distance where we evaluated the point, the closest boundary.

\section{Methods}

We used the CMA-ES algorithm on the gully headcut retreat model. This algorithm was run on a high-performance cluster at the University of Colorado, Boulder, using 12 nodes, each of which had 4 cores. The specified range of parameter values was normalized so that parameter values ranged from 0 to 1 . However, the constraint-penalty approach that we employed allowed parameter values to slightly exceed those bounds. An initial value for each parameter was randomly chosen from this range. In order to determine the fit between the model and the measured profile, we compared the modeled profile to the measured profile using the root mean squared error (RMSE) as the objective function.

Thirty independent trials of CMA-ES were run so that the parameter search would begin with thirty randomly selected initial parameter sets. This was done because Hansen and Ostermeier (2001) suggest that the quality of solutions found by CMA-ES using a small initial step-size are often determined by the location of the starting point (Hansen and Ostermeier, 2001). Within a single trial there were multiple iterations, and each iteration consisted of a model run with parameters specified by the CMA-ES algorithm. CMA-ES used the objective function output from each iteration to inform parameter value choices for the next iteration by mutating, that is, it varied the search steps stochastically and then selected the parameters that best minimized the objective function. A given trial run terminated once the parameters converged toward unique values, or the search-step size was equal to or less than $1 \times 10^{-6}$.

\section{Results and Discussion}

The CMA-ES approach resulted in far fewer iterations than would be required if a brute-force approach was used. If we explored 10 potential values for each of the 11 parameters, this would require more than 25 billion model runs to search every combination. Each model simulation takes approximately 20 minutes to completion, therefore a brute force approach would 
result in $5.2 \times 10^{11}$ minutes of model simulation time. By contrast, we found that in CMA-ES trials, the parameters often converged on an optimal value within 60-80 iterations (Figure 5a), and the resulting model profile obtained from parameters that minimized the objective function fit the target (i.e. observed) profile well (Figure 5b).

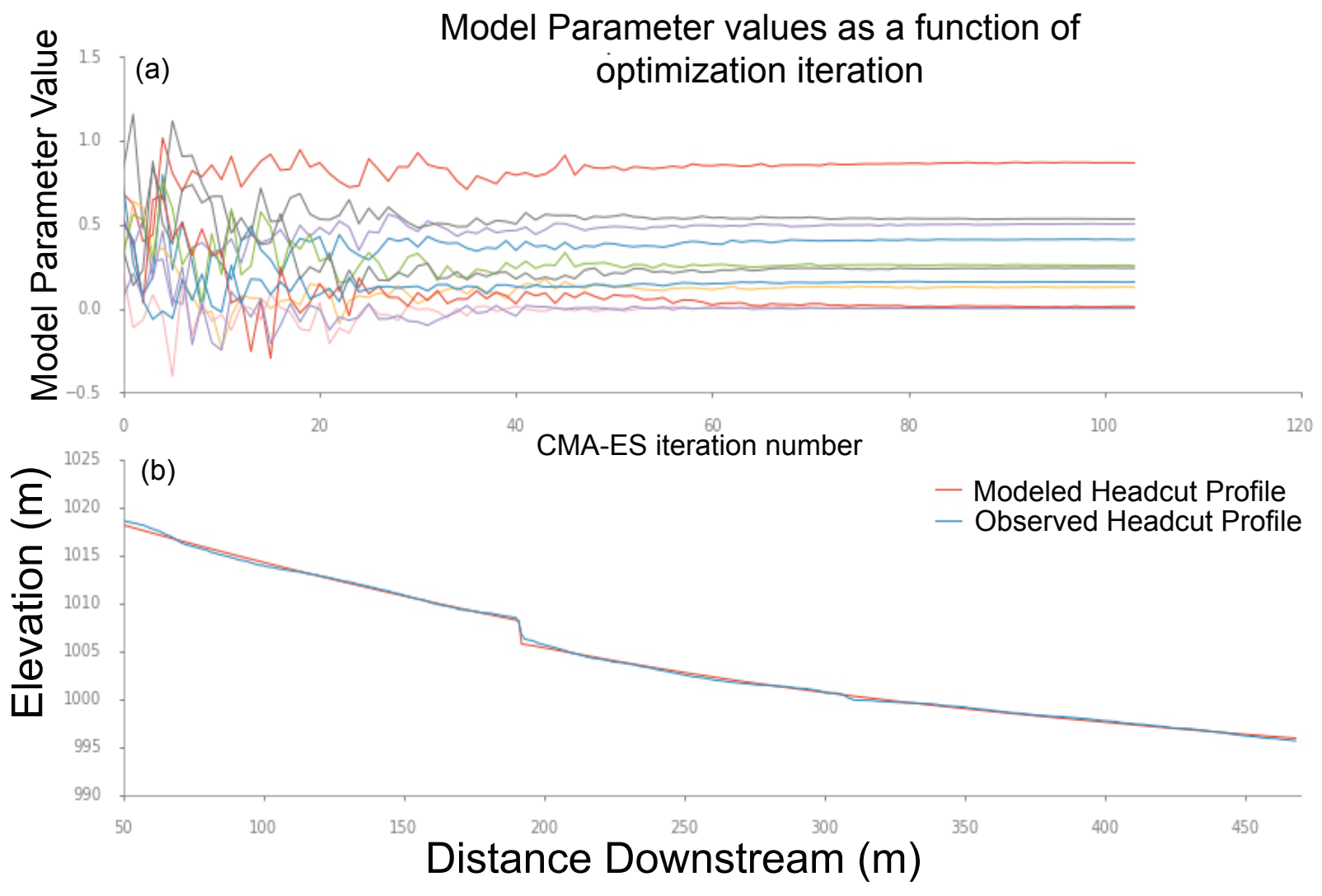

Figure 5: (a) Convergence of each variable toward an optimal value. (b) Modeled longitudinal profile of a gully with a headcut using the best-fit parameters $(\mathrm{RMSE}=17.5 \mathrm{~m}$ ), and compared to the measured longitudinal profile.

The optimal solution for each trial does not result in the same set of parameter values. This is due to the random initial parameter values chosen at the beginning of each trial. However, most of the solutions obtained from the CMA-ES parameter search resulted in a close fit between the modeled and measured longitudinal profile (Figure 6). This shows that the search algorithm can robustly discover potential optimal parameter values in a large 
solution space. Some optimal solutions from CMA-ES resulted in profiles that failed to match the measured headcut location (Figure 6), but these represented only four solutions within the top 18 model solutions.

We explored how each iteration of the 30 CMA-ES trial runs converged toward an optimal set of parameters, and found a duality within the final parameter values (Figure 7). Some parameters are highly sensitive and converge on a unique value. These are parameters that represent boundary conditions including: the starting profile shape $\left(z_{1}, z_{2}\right.$, and $\left.z_{3}\right)$, the starting headcut height $(h)$, and the model simulation time $(t)$. By contrast, parameters controlling competing geomorphic processes work in pairs such as precipitation and infiltration, the critical shear stress for grass versus bare soil, and the Manning's roughness coefficient for grass versus bare soil.

Our observation that the optimal parameter values for boundary conditions converge toward singular values supports the fact that landform evolution is dependent on the unique initial conditions of the landform. By contrast, the natural competition between geomorphic processes means that it is possible to change the value of parameters representing driving and resisting forces, and retain the same result. Therefore, it is not surprising that parameters representing competing processes can obtain different optimal parameter values and produce a similar result. For example, increasing precipitation and infiltration by the same magnitude will result in the same runoff depth. Likewise, a lower critical shear stress for bare soil will increase erosion in the bare soil areas, but a higher critical shear stress for grass will decrease erosion of grassy areas. The combination of these two parameter changes can result in a similar end-result for sedimentation. Changing Manning's roughness coefficient for bare and grassy areas in opposite directions can also result in a similar average flow velocity. Therefore, because these process-controlling parameters can take on multiple values but still produce a similar average value, a unique solution does not emerge.

This research suggests that a search algorithm for parameter values bridges the gap between picking parameters based on a range of observed estimates and inefficient, often intractable, brute-force parameter searches. Moreover, even with an efficient search algorithm, the inherent functionality of some parameter values will result in the potential for multiple optimized parameter estimates. Therefore, the ability of a search algorithm to identify parameters that converge toward singular values as well as those that oscillate between multiple values is a critical requirement for any potential strategy. This has implications for most geomorphic process models, which require many 


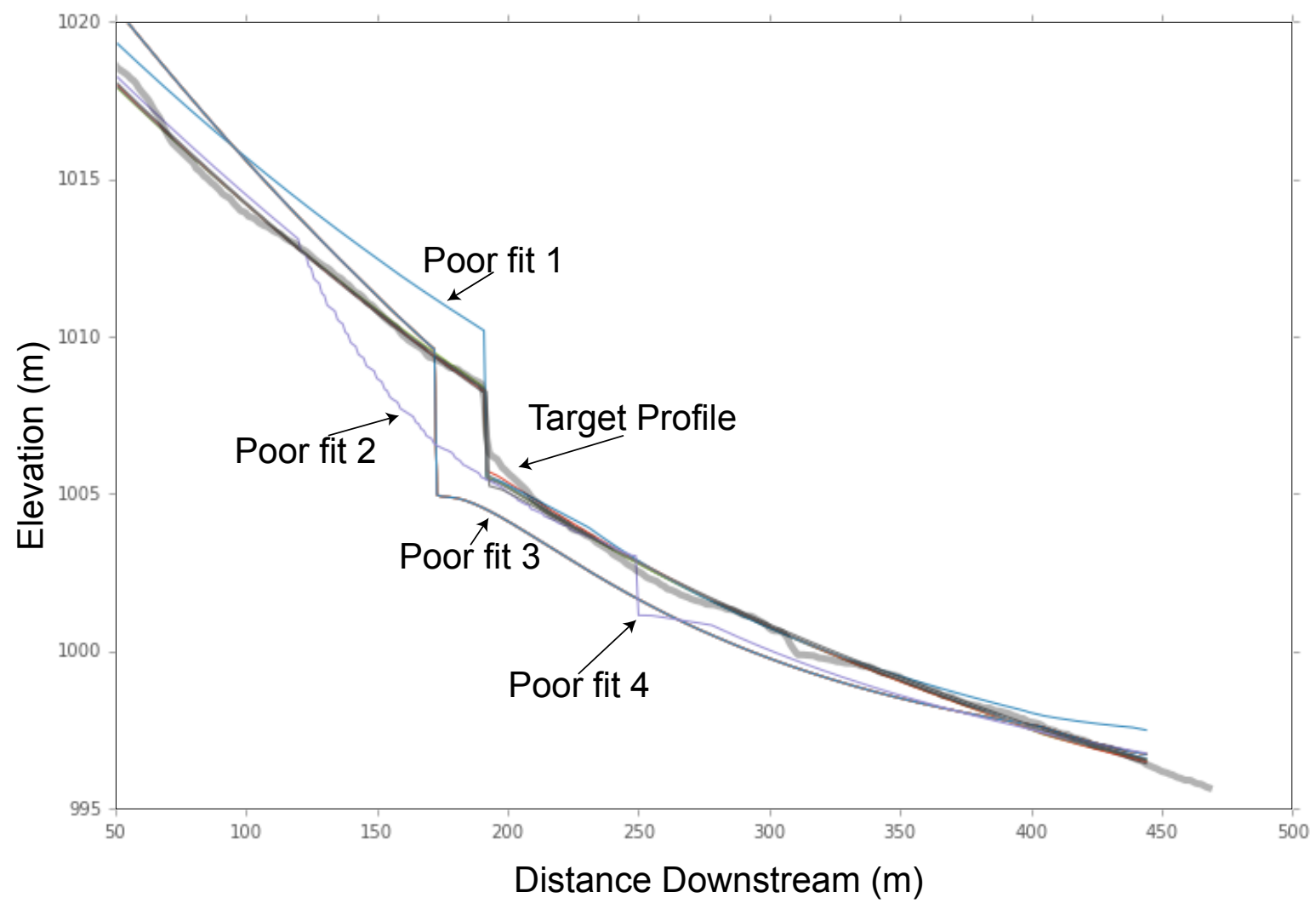

Figure 6: Simulated profiles compared to the measured headcut (dark gray). Fourteen of the model runs (the majority) provide a good fit to the observed headcut, but four solutions result in poor fits despite being the optimal solution suggested by CMA-ES. Note for clarity only the top $60 \%$ of the optimal parameter sets are displayed.

unconstrained parameters for competing processes.

While the overall objective of the optimization scheme was to simply 


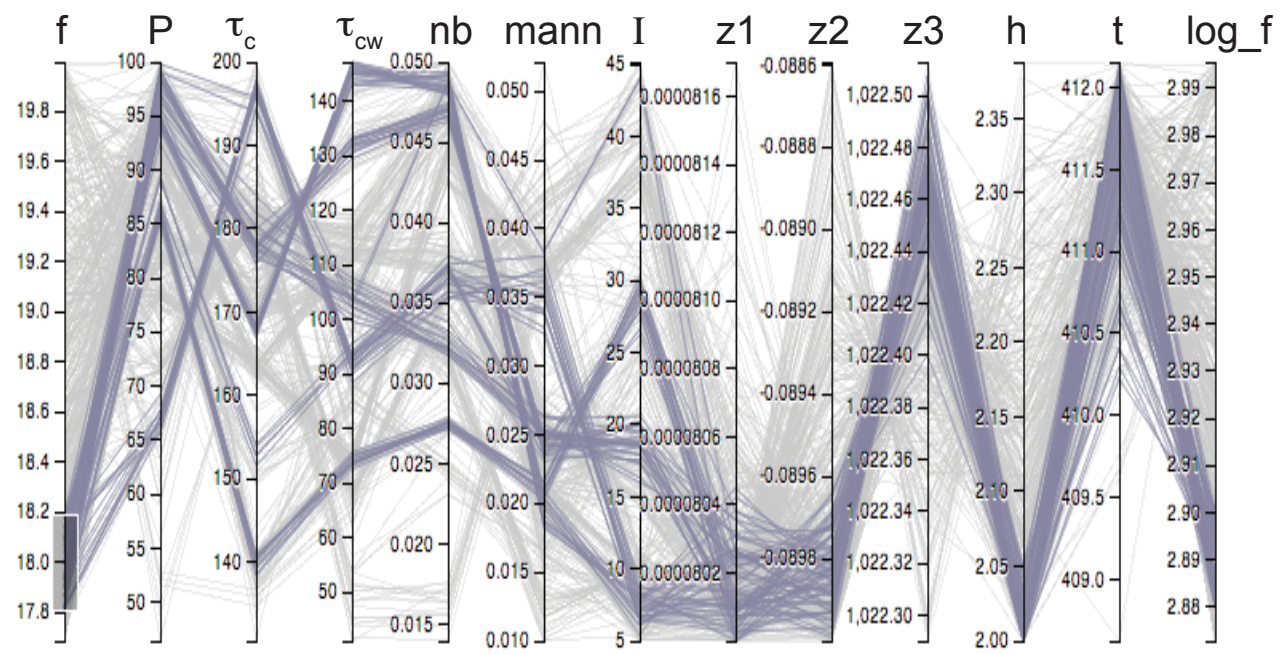

Figure 7: The parameter values for each iteration of the 30 CMA-ES trial runs. The objective function $(f)$ is highlighted in blue for the parameter values that all led to the lowest differences between the model and the measured profile. Less optimal value of $f$ are displayed in gray. The parameter names are defined in Table 1.

obtain parameter values, the technique revealed important insight into the nature of the parameters in the underlying model. The duality of the parameters (unique versus multi-value convergent) showed that parameters representing competing processes do not result in a single optimal parameter value. These also tend to be the parameters that govern geomorphic processes. However, the boundary conditions can be fit uniquely, and this allowed us to find the initial headcut height and slope geometry that best corresponded to the conditions leading to a final gully shape.

\section{Conclusions}

By using an optimization algorithm and leveraging high-performance cluster resources, it is possible to identify parameter values that lead to best-fit model solutions. In the context of a one-dimensional model of gully headcut propagation the optimized results using CMA-ES show that boundary condition parameters converge toward a singular value. These boundary condition values provide estimates of the initial longitudinal profile shape and gully headcut height, which were not known a priori. While it is unlikely that our optimal results are the exact initial boundary conditions experienced in 
the gullies at our field site, this approach provides an objective methodology for specifying the unknown boundary conditions. At a minimum, parameter optimization is a way to exclude possible initial boundary condition scenarios in landform evolution models, where initial conditions are rarely constrained.

This study further showed that parameters controlling geomorphic processes can occupy several different optimal values. The average runoff depth, velocity, and erosion rate in the gully model result from competing processes. We found that it was possible to change competing parameter values governing these processes and obtain a similar optimal result. It is therefore likely that there will always be a range of parameter values for competing processes that converge toward equally optimal solutions. The CMA-ES approach is nevertheless helpful in identifying the range wherein it is possible to vary competing parameters and maintain an optimal solution. Furthermore, this study shows that CMA-ES is an efficient approach for exploring multiple combinations of parameter value choices, thus allowing a tractable alternative to brute-force searching of the parameter space.

\section{Acknowledgements}

We gratefully acknowledge the support for this study by the National Science Foundation grant EAR-0952247 (GT) and the use of the Janus highperformance cluster at the University of Colorado. We are also appreciative of thoughtful review comments provided by two anonymous reviewers.

\section{References}

Barclay, R. S., Johnson, K., Betterton, W., Dilcher, D., 2003. Stratigraphy and megaflora of a K-T boundary section in the eastern Denver Basin, Colorado. Rocky Mountain Geology 38 (1), 45-71.

Barkwith, A., Hurst, M. D., Jackson, C. R., Wang, L., Ellis, M. A., Coulthard, T. J., 2015. Simulating the influences of groundwater on regional geomorphology using a distributed, dynamic, landscape evolution modelling platform. Environmental Modelling \& Software 74, 1-20.

Bradford, J., Piest, R., 1980. Erosional development of valley-bottom gullies in the upper midwestern United States. In: Coates, D. R., Vitek, J. D. (Eds.), Thresholds in Geomorphology. Allen and Unwin: London, pp. 75101. 
Chow, V., 1959. Open-Channel Hydraulics. McGraw-Hill Book Co.

Davy, P., Lague, D., 2009. Fluvial erosion/transport equation of landscape evolution models revisited. Journal of Geophysical Research 114 (F3), F03007.

DeLong, S. B., Johnson, J., Whipple, K., 2014. Arroyo channel head evolution in a flash-flood-dominated discontinuous ephemeral stream system. The Geological Society of America Bulletin.

Dietrich, W., Dunne, T., 1993. The channel head. In: Beven, K., Kirkby, M. J. (Eds.), Channel Network Hydrology. Wiley: Chichester, pp. 175219.

Dietrich, W. E., Bellugi, D. G., Sklar, L. S., Stock, J. D., Heimsath, A. M., Roering, J. J., 2003. Geomorphic transport laws for predicting landscape form and dynamics. In: Prediction in geomorphology.

Elliot, W. J., Liebenow, A. M., Laflen, J. M., Kohl, K. D., Aug. 1989. A compendium of soil erodibility data from WEPP cropland soil field erodibility experiments 1987 and 1988. Tech. rep., Ohio State University, and USDA-ARS, West Lafayette, Indiana.

Gardner, T., 1983. Experimental study of knickpoint and longitudinal profile evolution in cohesive, homogeneous material. Bulletin of the Geological Society of America 94 (5), 664-672.

Gilbert, G., Hall, W., 1907. Rate of recession of Niagara Falls. US Government Printing Office.

Hack, J., 1957. Studies of longitudinal stream profiles in Virginia and Maryland. US Geological Survey Professional Paper 294-B (1).

Hansen, N., Kern, S., 2004. Evaluating the cma evolution strategy on multimodal test functions. In: Parallel problem solving from nature-PPSN VIII. Springer, pp. 282-291.

Hansen, N., Niederberger, A. S., Guzzella, L., Koumoutsakos, P., 2009. A method for handling uncertainty in evolutionary optimization with an application to feedback control of combustion. Evolutionary Computation, IEEE Transactions on 13 (1), 180-197. 
Hansen, N., Ostermeier, A., 2001. Completely Derandomized SelfAdaptation in Evolution Strategies. Evolutionary Computation 9 (2), 159 195.

Howard, A., McLane, C., 1988. Erosion of cohesionless sediment by groundwater seepage. Water Resources Research 24 (10), 1659-1674.

Istanbulluoglu, E., Bras, R., Flores-Cervantes, H., Tucker, G., 2005. Implications of bank failures and fluvial erosion for gully development: Field observations and modeling. Journal of Geophysical Research 110 (F1), F01014.

Montgomery, D. R., 1999. Erosional processes at an abrupt channel head: Implications for channel entrenchment and discontinuous gully formation. In: Darby, S., Simon, A. (Eds.), Incised River Channels. John Wiley and Sons, Inc., pp. 247-276.

N. Hansen and S.D. Müller and P. Koumoutsakos, 2003. Reducing the time complexity of the derandomized evolution strategy with covariance matrix adaptation (CMA-ES). Evolutionary Computation 11(1), 1-18.

National Center for Airborne Laser Mapping, May 2007. Project Report: West Bijou Creek, CO LiDAR Survey. https://cloud.sdsc.edu/v1/ AUTH_opentopography/www/metadata/NCALM/CO07_Tucker_report. pdf.

Prosser, I., Dietrich, W., 1995. Field experiments on erosion by overland flow and their implication for a digital terrain model of channel initiation. Water Resources Research 31 (11), 2867-2876.

Rengers, F. K., Tucker, G., 2014. Analysis and modeling of gully headcut dynamics, North American high plains. Journal of Geophysical Research: Earth Surface.

Rengers, F. K., Tucker, G., 2015. The evolution of gully headcut morphology: a case study using terrestrial laser scanning and hydrological monitoring. Earth surface processes and landforms.

Sharma, M., Gander, G., Hunt, C., 1980. Spatial variability of infiltration in a watershed. Journal of Hydrology 45 (1), 101-122. 
Sidorchuk, A., 1999. Dynamic and static models of gully erosion. Catena 37 (3), 401-414.

Stein, O., Julien, P., 1993. Criterion delineating the mode of headcut migration. Journal of Hydraulic Engineering 119 (1), 37-50.

Stein, O., LaTray, D., 2002. Experiments and modeling of head cut migration in stratified soils. Water Resources Research 38 (12), 1284.

Tucker, G. E., 2009. Natural experiments in landscape evolution. Earth surface processes and landforms.

Tucker, G. E., Hancock, G. R., 2010. Modelling landscape evolution. Earth Surface Processes and Landforms 35 (1), 28-50.

Verachtert, E., Van Den Eeckhaut, M., Poesen, J., Deckers, J., 2010. Factors controlling the spatial distribution of soil piping erosion on loess-derived soils: A case study from central Belgium. Geomorphology 118 (3), 339-348.

Wohl, E., Greenbaum, N., Schick, A., Baker, V., 1994. Controls on bedrock channel incision along Nahal Paran, Israel. Earth Surface Processes and Landforms 19 (1), 1-13.

Woodward, D., 1999. Method to predict cropland ephemeral gully erosion. Catena 37 (3), 393-399. 